\title{
Entomopathogenic nematode- Heterorhabditis indica and its compatibility with other biopesticides on the Greater wax moth- Galleria mellonella (L.)
}

\author{
M. Sankar ${ }^{a}{ }^{*}$, V. Sethuraman ${ }^{\mathrm{b}}$, M. Palaniyandi ${ }^{\mathrm{b}}$ and J. S. Prasad ${ }^{\mathrm{a}}$ \\ ${ }^{a}$ Directorate of Rice Research, Rajendranagar, Hyderabad, Andhra Pradesh-560001, India \\ ${ }^{b}$ Department of Biotechnology, Bharathidasan University, Tiruchirappalli, Tamil Nadu-620024, India \\ shankarms10@gmail.com*, sethuramanbio@gmail.com, pmkpalani@gmail.com, jsprasad24@yahoo.com
}

\begin{abstract}
Pathogenic effect of an indigenous entomopathogenic nematode, Heterorhabditis indica and commercial biopesticides of three fungal pathogens ( $M$. anisopliae, $B$. bassiana and $T$. viride), one antagonistic bacteria ( $P$. fluorescence), and two neem based biopesticides (Neem and Nimor) were tested on the Greater wax moth, Galleria mellonella larva under laboratory condition. The efficacy of the biopesticides was tested individually or in combination with $H$. indica. Pathogenic interaction on $G$. mellonella larva by $H$. indica and biopesticides was assessed at every twelve hour interval after storage. Significant differences in the percentage of larval mortality were determined among the biopesticide treatments. When tested in isolation, $B$. bassiana imposed greater mortality on host larva (40\%) when compared to other biopesticides; while $P$. fluorescence and $H$. indica combination proved to be the most efficient causing $100 \%$ mortality on $G$. mellonella after $24 \mathrm{~h}$ of storage. Progeny produced by $H$. indica on single $G$. mellonella was found to be more (140108 IJs/larva) in the combination treatment with $T$. viride. Pathogenicity influence of $H$. indica when exposed with other biopesticides on host larva, have proved to be more virulent and compatible. The results on pathogenicity of entomopathogenic nematode- $H$. indica on $G$. mellonella larvae are a novelty in the field of biological control. Understanding the interactions between entomopathogenic nematodes and other soil microorganisms may be the key for success in IPM programme.
\end{abstract}

Keywords: Heterorhabditis indica, Galleria mellonella, biopesticides, biological control.

Introduction

Insecticides such as viruses, bacteria, fungi, protozoa, and nematodes can offer effective alternatives to replace chemicals under IPM programme. The greatest strength is their host specificity as most are essentially nontoxic and non-pathogenic to wildlife, humans, and other non target organisms. Several microbial pathogens such as; Bacillus penetrans, Pseudomonas fluorescence, Bacillus thuringiensis, Trichoderma viride, Beauveria bassiana and Metarhizium anisopliae have been developed and being commercialized to control various economically important crop pests and diseases (Ignacimuthu,
2008). Number of farmers use neem (Azadirachta indica A. Juss; Meliaceae) as pesticidal, antifungal, and antifeedant agent. The opportunities for using entomopathogenic nematodes against insect pests in the soil and cryptic habitats in agricultural pest are excellent (Gaugler, 2002). Entomopathogenic nematodes appear to be compatible with many herbicides, fungicides, acaricides, insecticides, nematicides (Georgis \& Kaya, 1998; Rovesti \& Dese, 1990) azadirachtin (Stark, 1996), Bacillus thuringiensis (Kaya et al., 1995). On the other hand, synergistic interaction between entomopathogenic nematodes with various insecticides (Koppenhofer et al., 2000) and pathogens (Thurston et al., 1994; Koppenhofer et al., 1999) has been observed. Our focus in this paper is on an indigenous entomopathogenic nematode- Heterorhabditis indica associated with mutualistic bacteria- Photorhabdus luminescence complex exposed together with other biopesticides (M. anisopliae, B. bassiana and $T$. viride, $P$. fluorescence, Neem and Nimor) at various periods, how that works together as a biological control unit to kill an insect larva- G. mellonella used as a common host for all the biopesticides.

Material and methods

Insect culture

The laboratory common host, Greater wax moth, Galleria mellonella (L.) reared on artificial diet as described by Singh (1994) at a constant temperature of $27 \pm 2^{\circ} \mathrm{C}$ and $65 \pm 5 \%$ R.H. The final instar larvae (25 days old) were utilized for mass rearing of entomopathogenic nematode, $H$. Indica and the experiment purpose.

Nematode culture

Infective juveniles (IJs) of entomopathogenic nematode, Heterorhabditis indica Poinar, Poinar et al., (1992) isolated from naturally infected larvae of Greater wax moth, G. mellonella collected from deserted honey comb in research farm at Directorate of Rice Research (DRR), Hyderabad and, the multiplied IJs were harvested through modified White trap (White, 1927) after incubating 7 to 9 days at room temperature $\left(27 \pm 2^{0} \mathrm{C}\right)$. Freshly harvested IJs were surface sterilised in formalin $(0.1 \%)$ solution and stored in distilled water with a drop of Triton X-100 (0.5\%). Nematode concentration was maintained at 2000 $\mathrm{IJs} / \mathrm{ml}$ in tissue culture flasks (100 ml/flask) and the 
stock suspension was regularly replaced by changing fresh water at 2 weeks interval. The dose of nematodes was prepared either by direct count or dilution count as described by Woodring and Kaya (1988). The stock suspension was concentrated by centrifugation at $500 \mathrm{rpm}$ for 10 min. to settle the IJs and the supernatant was decanted. Further, required dilutions of the suspension were prepared using distilled water.

Biopesticides

The most commonly used biopesticides in the experiments such as; entomopathogenic fungi, Beauveria bassiana (Baba) and Metarhizium anisopliae (Metarhizium), antagonistic fungi, Trichoderma viridae (Nisarga), antagonistic bacteria, Pseudomonas fluorescence (Sparsha) and the botanical biopesticides, Neem-3000 ppm (Multineem) and Nimore-1500 ppm (Nimbicidine) (manufactured by M/s Multiplex Agricare Pvt. Ltd., Bangalore, India) was diluted separately in $100 \mathrm{ml}$ nematode $(H$. indica at $200 \mathrm{IJs} / \mathrm{ml})$ suspension to prepare a storage flask and five such kind of replicates were made it to all the biopesticides individually followed by the field recommended concentrations viz., B. bassiana, M. anisopliae, $T$. viridae, $\left(1 \times 10^{9}\right.$ spores $\left./ \mathrm{ml}\right), P$. fluorescence $(1 \mathrm{X}$ $10^{9} \mathrm{CFU} / \mathrm{ml}$ ) and Neem (3000 ppm) and Nimore (1500 ppm) as procedure given in the label by the company. Each biopesticide was considered as one treatment and each treatment has five replicates. All the flasks were stored for $60 \mathrm{~h}$ duration to find out the interaction with nematodes.

\section{Bioassays}

Bioefficacy of each biopesticide was evaluated at an every $12 \mathrm{~h}$ intervals by inoculating on a final instar larva of $G$. mellonella at $1 \mathrm{ml}$ suspension obtaining from each flask as topical application to the larva released on Whatman's No-1 filter paper lined in Petri dish $(9 \mathrm{~cm}$ dia.). Each treatment was replicated 20 times and the experiment was repeated twice to confirm the results. Care was taken for accurate number of IJs and other biopesticides while inoculation to the larva. The mean percent mortality of $G$. mellonella larva killed by each biopesticides was recorded. Microscopic observations and the growth of biopesticides on larva was confirmed the result of infection and death. After death, each cadaver was individually transferred to White trap and allowed them to multiply (nematodes or fungi or bacteria if any) for 8-10 days with suitable moisture. The percent mortality of larva caused either by fungi / bacteria / neem or $H$. indica was identified under microscopic observation (Nikon SMZ 800, Japan). The progeny produced by nematodes (if any) was harvested by White trap method and the total recovery of nematodes/larva was worked out. Data were analysed and subjected to ANOVA or factorial analysis of variance (FANOVA) and statistical significance was judged at the level $(P<$ $0.05)$.

Results

\section{Pathogenicity}

The level of larval mortality on G. mellonella varied and depended on the type of treatment. All treatments gave an excellent lethal effect against G. mellonella. Among various biopesticides treatments (12 $\mathrm{h}$ of exposure) in isolation, the mortality rate of $G$. mellonella infected by $P$. fluorescence recorded higher (49.42\%) when compared to that of T. viride (47\%) and Nimor (42.28\%). When assessed for the combined lethal effect on $G$. mellonella larva caused by $H$. indica and other biopesticides, the synergistic effect of $H$. indica and $P$. fluorescent brought $100 \%$ complete mortality in $24 \mathrm{~h}$ of exposure. But the IJs of $\mathrm{H}$. indica combined with Neem, Nimor and T. viride also resulted in $100 \%$ mortality but after $48 \mathrm{~h}$ of interaction. However, the IJs combination with $M$. anisopilae and, $B$. bassiana required more time (60 h) of interaction to cause the same level of insect mortality (Fig.1).

Fig 1. Percent mortality of G. mellonella larva exposed to various biopesticides

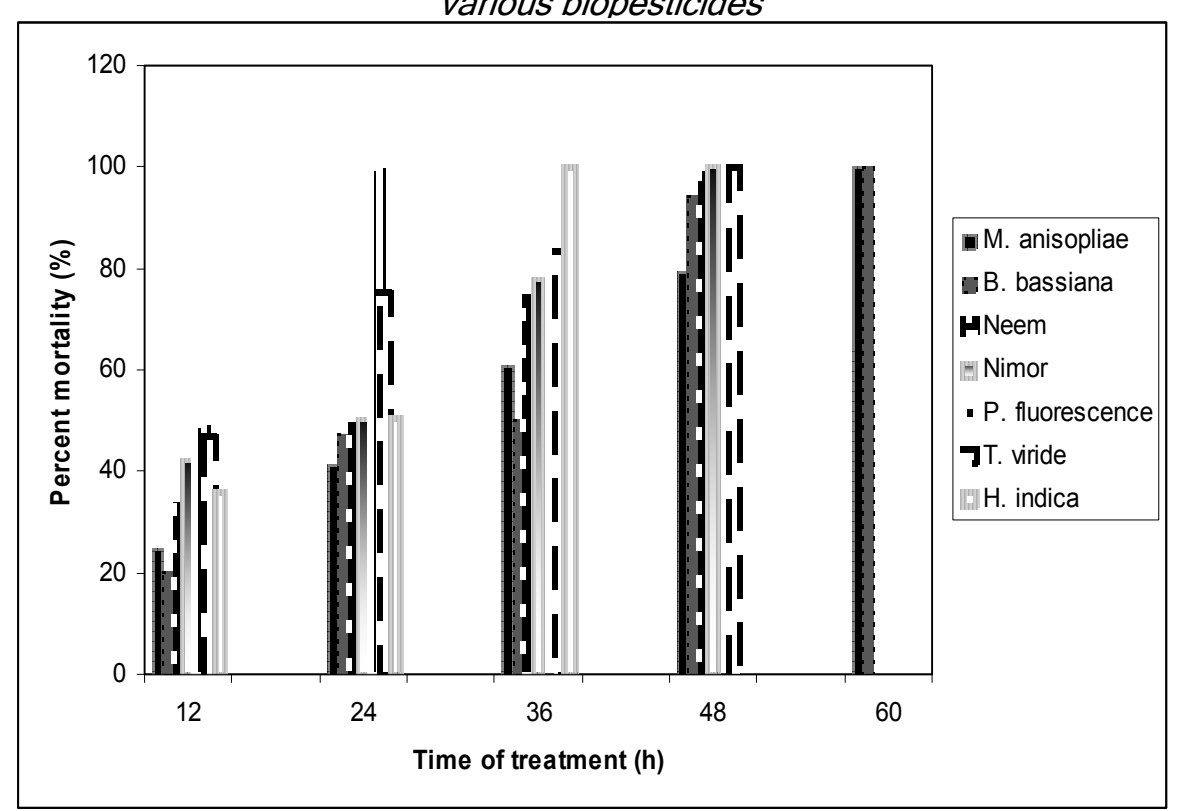


Fig. 2. Percent larval mortality influenced by individual biopesticides treated in combination with $\mathrm{H}$. indica on Galleria mellonella.

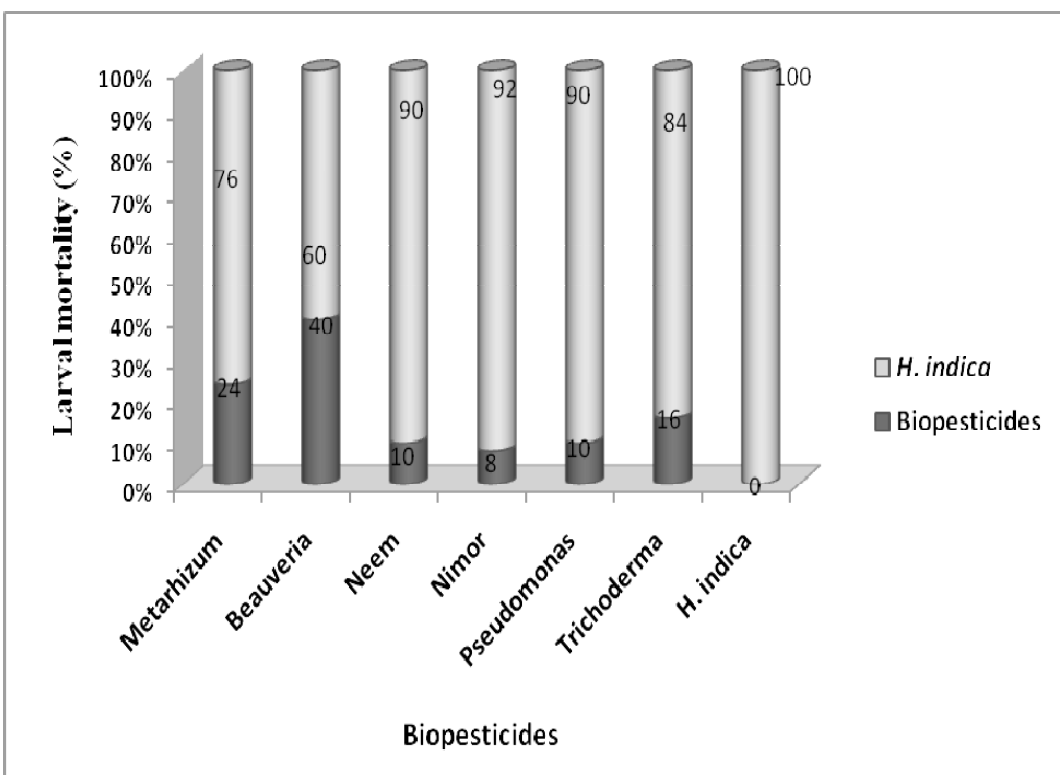

http://www.indjst.org Vol.2 No 1 (Jan. 2009)

approximately $12-15$ days. In control treatment, the recovery from $G$. mellonella larva exposed to $H$. indica alone yielded better results. The recovery of nematodes and the mean number of nematodes emerging from each host larva was ranging from 161559 to 134374 IJs/larva (CD $(0.05)=62.85)$ than they applied in combination with other biopesticides. Among the treatments, $H$. indica and $T$. viride combination resulted in producing the highest number of infective juveniles and ranged from 140108 to $123961 \mathrm{IJs} / \mathrm{larva}$. However, the larvae produced nematodes with $P$. fluorescence combination treatments did not influence the recovery and it was statistically on par ranging from 126080 to 112690 IJs/larva. The results

The investigation on pathogenicity of entomopathogenic nematode- $H$. indica on $G$. mellonella larvae is a novelty in the field of biological control. Maximum mortality of insects $(100 \%)$ was also achieved when they were treated with $H$. indica alone in a control treatment. By the individual statistical analysis of all competition bioassay treatments with $H$. indica, a statistically significant influence on larval mortality caused by $H$. indica was found to be more with the combination treatment of Neem (90\%), Nimore (92\%) and $P$. fluorescence (90\%) on G. mellonella. No such influence was determined with the other three biopesticides such as; $T$. viride (84\%), $M$. anisopliae (76\%), and B. bassiana (60\%) (Fig.2).

Among the biopesticides exposed with $H$. indica and treated to G. mellonella larva, the mortality rate influenced by $B$. bassiana was significantly more $(40 \%)$ than the other treatments (M. anisopliae, T. viride, and $P$. fluorescence) with increasing the growth of spores and mycelia (24\%, $16 \%$ and $10 \%$ respectively). The percent larval mortality of $G$. mellonella was significantly low by Neem (10\%) and Nimor (8\%) treated with $H$. indica combination and those cadavers did not support for nematode multiplication thus the death was consider due to neem activities (Fig. 2).

\section{Nematodes recovery}

The combined effect of biopesticides- fungi, bacteria and neem treatments with $H$. indica adversely affected the multiplication of nematodes on G. mellonella larva. The emergence of infective nematode stages from the nematode-killed wax moth larvae infected by $H$. indica began on day $9^{\text {th }}$ after the host's death and continued for obtained in this study reveal that the total mean recovery of nematodes was significantly less in number and was varied from 91152 to 72638 and from 87598 to $67703 \mathrm{IJs} /$ larva by the combination treatments of $H$. indica exposed in Nimor and $B$. bassiana respectively (Table 1 ).

\section{Discussion}

Pathogenicity

The study provides evidence that all treatments had significant effect on the incidence of the disease $(p \leq 0.05)$ and the efficacy of control. The results obtained in the study on percent larval mortality influenced by $H$. indica exposed with $P$. fluorescence, $T$. viride and Nimor recorded significantly higher efficacy i.e., $49.42 \%, 47.00 \%$ and $42.28 \%$ respectively after $12 \mathrm{~h}$ of interaction. The pathogenic effect caused on G. mellonella larva was completed within $24 \mathrm{~h}$ with an interaction of $P$. fluorescence and $H$. indica, whereas in the control treatment $(H$. indica alone) took $36 \mathrm{~h}$ to cause the same level of mortality. It is in close agreement with Hara and Kaya (1982) reported that the nematodes are symbiotically associated with a mutualistic bacterium, which allows them to kill their hosts quickly ( 36 to $48 \mathrm{~h}$ ) and thus gives them an advantage over other predators, parasitoids and pathogens. The IJs of $H$. indica treated together with neem based pesticides, Neem and Nimor combination took $48 \mathrm{~h}$ for $100 \%$ larval mortality. Gaffney et al., (2005) investigated that treatment with azadirachtin completely stopped the physiological development of larvae of Otiorhynchus sulcatus within $48 \mathrm{~h}$ of treatment which showed the growth-disruptive properties of 
Table 1. Progeny produced by H. indica on G. mellonella larva exposed in biopesticides.

\begin{tabular}{|c|c|c|c|c|c|c|c|}
\hline \multirow{2}{*}{$\begin{array}{l}\text { Time }(\mathrm{h}) \\
\quad \text { of } \\
\text { treatment }\end{array}$} & \multicolumn{7}{|c|}{${ }^{*}$ Multiplication of $H$. indica (numbers) } \\
\hline & M. anisopliae & B. bassiana & Neem & Nimor & $P$. florescence & T. viride & H. indica \\
\hline 12 & $104534(305)$ & $\begin{array}{c}87598 \\
(297)\end{array}$ & $\begin{array}{c}12063 \\
4(345)\end{array}$ & $\begin{array}{c}91152 \\
(287)\end{array}$ & $\begin{array}{c}126080 \\
(357)\end{array}$ & $\begin{array}{c}140108 \\
(372)\end{array}$ & $\begin{array}{c}161559 \\
(400)\end{array}$ \\
\hline 24 & $\begin{array}{c}98580 \\
(298)\end{array}$ & $\begin{array}{l}79831 \\
(274) \\
\end{array}$ & $\begin{array}{c}10531 \\
8(312) \\
\end{array}$ & $\begin{array}{c}89328 \\
(280) \\
\end{array}$ & $\begin{array}{c}122845 \\
(347) \\
\end{array}$ & $\begin{array}{c}131114 \\
(360) \\
\end{array}$ & $\begin{array}{c}151093 \\
(385) \\
\end{array}$ \\
\hline 36 & $\begin{array}{c}96682 \\
(310)\end{array}$ & $\begin{array}{c}74537 \\
(271)\end{array}$ & $\begin{array}{c}10442 \\
9(319)\end{array}$ & $\begin{array}{c}86605 \\
(290)\end{array}$ & $\begin{array}{c}118164 \\
(348)\end{array}$ & $\begin{array}{c}125322 \\
(354)\end{array}$ & $\begin{array}{c}157967 \\
(397)\end{array}$ \\
\hline 48 & $\begin{array}{c}95234 \\
(312)\end{array}$ & $\begin{array}{c}71430 \\
(264)\end{array}$ & $\begin{array}{c}95918 \\
(308)\end{array}$ & $\begin{array}{c}77747 \\
(276)\end{array}$ & $\begin{array}{c}115448 \\
(323)\end{array}$ & $\begin{array}{c}124778 \\
(354)\end{array}$ & $\begin{array}{c}157450 \\
(397)\end{array}$ \\
\hline 60 & $\begin{array}{l}81477 \\
(286)\end{array}$ & $\begin{array}{l}67703 \\
(259)\end{array}$ & $\begin{array}{c}89382 \\
(284)\end{array}$ & $\begin{array}{c}72638 \\
(266) \\
\end{array}$ & $\begin{array}{c}112690 \\
(337)\end{array}$ & $\begin{array}{c}123961 \\
(353) \\
\end{array}$ & $\begin{array}{c}134374 \\
(347) \\
\end{array}$ \\
\hline $\mathrm{CD}(0.05)=$ & 78.78 & 23.16 & 79.38 & 70.12 & 62.18 & 18.92 & 62.85 \\
\hline
\end{tabular}

*Figures in the parentheses represent Sqrt transformed. *original values

neem formulations. Zimmerman (1996) and Tkaczuk et al., (2005) reported that all the stages of Otiorhynchus sulcatus are susceptible to the entomopathogenic fungi Beauveria brongniartii treated along with neem formulations, but the total mortality after different treatments was not statistically different. Among the treatments, in the combined effect between $H$. indica exposed with $M$. anisopliae and $B$. bassiana took maximum of $60 \mathrm{~h}$ to extend their complete mortality on $G$. mellonella. Such could be the reason that the interaction between the entomopathogenic nematodes and fungi by tough competitions stress, may loose their infectivity and the larvae may acquire resistant against them.

All groups of pathogens (bacteria, fungi, neem, and nematodes) have shown at least some pathogenicity to $G$. mellonella larva. Investigations found in this study demonstrate the antimycotic substances produced by $\mathrm{H}$. indica on associated bacteria, Xenorhabdus luminescence may inhibit growth of fungi and bacteria. Gottwald and Tedders (1983) observed $<30$ and $6 \%$ larval mortality from $B$. bassiana and $M$. anisopliae applications, respectively using relatively high rates (up to $10^{7}$ conidia/g soil) against pecan weevil. It is in support of our investigations that the level of mortality (\%) caused on $G$. mellonella by $B$. bassiana was more $(40 \%)$ than the other treatments $(M$. anisopliae (24\%), T. viride (16\%), and P. fluorescence (10\%). The larval infection was confirmed with increased growth of fungi/ bacteria after 3 days of infection. Inam-Ul-Haq et al., (1997) reported that the antimycotic substances produced by Xenorhabdus spp., inhibit the growth of $F$. oxysporum and $F$. lycopersici and the toxins are their most likely mode of action in suppressing the pathogen. The toxic action of most microbial insecticides is specific to a single group or species of insects and this specificity means that most microbial insecticides do not directly affect the other beneficial organisms in treated areas. Data presented in Fig. 1 shows that the entomopathogenic nematode, $H$. indica proved maximum level of larval mortality on $G$. mellonella and proved to be a potential control agent among the biopesticides. In competition bioassay, Shapiro-llan et al., (2002) observed >90\% suppression of $C$. nenuphar larvae with $S$. riobrave when they treated along with pathogens.

\section{Multiplication}

Understanding the interactions between entomopathogenic nematodes and other soil microorganisms may be the key for success in IPM programme. Differences between the reproduction potential of entomopathogenic nematodes may be related to the isolates, species, host susceptibility, number of bacteria proliferating in the host, invasion rate, and environment. It is possible that differences in virulence between species and other biotic factors might be greater for a less susceptible host. The effectiveness of $H$. indica exposed with $T$. viride increased through a synergistic relationship and sub lethal doses of the insecticide causing $>84 \%$ of larval mortality and well supported to produce maximum number of yield $129056 \mathrm{IJs} / \mathrm{larva}$ varied from 123961 to 140108 IJs/larva on G. mellonella. However, the total mean recovery of nematodes was not affected when the IJs exposed upto $60 \mathrm{~h}$ in antagonistic bacteria, $P$. fluorescent recording $119045 \mathrm{IJs} /$ larva and varied from 126080 to 112690 IJs/larva. Results of this study is in close agreement aaccording to Poinar, entomopathogenic 
nematodes can be reared by in vivo methods, with yields of 100,000-200,000 infective stage juveniles per G. mellonella larva. However, an average production is much less, from the cadaver infected by IJs exposed in Neem and $M$. anisopliae yielding with an average of 103136 and 95301 infectives per insect respectively and we could not attain such great numbers of nematodes when the IJs exposed in Nimore and $B$. bassiana suspensions (83494 and 76219 IJs/larva respectively). It is in clear understood that biopesticides such as $B$. bassiana, $M$. anisopliae and neem are not supported the host definitely affecting the total number of IJs developing inside the cadaver. In biological-control campaigns, it is vital to know whether releasing one natural enemy against a pest is likely to be more effective than the release of many, especially where competition between enemies might reduce their overall effectiveness (Selvan et al., 1993). As Gaugler and Kaya (1990) reported, the combination of 2 nematode species with different search strategies to control 1 or 2 susceptible insect pest species in a soil habitat appears feasible. Indeed, combinations of different nematode species and other biological control agents may increase their overall efficacy against an insect pest (Stiling, 1992).

Conclusion

The benefits of utilizing entomopathogenic nematodes combined with other microbial pesticides can offer better control management IPM programme compared to that of broad spectrum insecticides. Apart from the reduction of non-target impacts, potential benefit as tools for resistance management, safety for applicators, and no re-entry or pre-harvest interval growth are important when a sustainable IPM system is considered.

\section{References}

1. Gaffney MT, Maher M and Purvis G (2005) Efficacy of Metarhizium anisopliae and neem seed kernel for the control of Otiorhynchus sulcatus in nursery stock containers. In: Proceedings of Agricultural Research Forum. Tullamore, 34.

2. Gaugler R (2002) Entomopathogenic Nematology. CABI Publishing. Wallingford, UK.

3. Gaugler R and Kaya HK (1990) Entomopathogenic Nematodes in Biological Control, CRC Press Inc., Boca Raton, 349.

4. Georgis R and Kaya HK (1998) Formulation of entomopathogenic nematodes. In: Formulation of Microbial Biopesticides: Beneficial Microorganisms, Nematodes and Seed Treatments. (Ed. Burges HD) Kluwer, Dordrecht, The Netherlands. pp. 289-308.
5. Gottwald TR and Tedders WL (1983) Suppression of pecan weevil (Coleoptera: Curculionidae) populations with entomopathogenic fungi. Environ. Entomol. 12, 471-474.

6. Hara AH and Kaya HK (1982) Effects of selected insecticides and nematicides on the in vitro development of the entomogenous nematode Neoaplectana carpocapsae. J. Nematol. 14(4), 486-491.

7. Ignacimuthu IC (2008) Ecofriendly insect pest management. National Symposium on 'Ecofriendly Insect Pest Management,' 7-8 February 2008 at the Entomology Research Institute, Loyola College, Chennai. Curr. Sci. 94,10 .

8. Inam-UI-Haq M., Gowen SR, Javed N, Shahina IF, Izhar-Ulhaq $M$, Humayoon $M$ and Pembroke B (1997) Antagonistic potential of bacterial isolaes associated with entomopathogenic nematodes Against tomato wilt caused by Fusarium oxysporum F.sp., lycopersici under greenhouse conditions, Pak. J. Bot. 39(1), 279-283.

9. Poinar GO, Karunakar GK and David $\mathrm{H}$ (1992). Heterorhabditis indicus $\mathrm{n}$. sp.(Rhabditida: Nematoda) from India: separation of Heterorhabditis spp. by infective juveniles. Fundamental and Applied Nematology 15: 467-472.

10. Kaya HK, Burlando TM and Choo HY (1995) Integration of entomopathogenic nematodes with Bacillus thuringiensis or pesticidal soap for control of insect pests. Biol. Control. 5, 432441.

11. Koppenhofer AM, Brown IM and Gaugler R (2000) Synergism of imidacloprid and entomopathogenic nematodes: greenhouse and field evaluation. Biol. Control. 19, 245-251.

12. Koppenhofer AM, Choo HY and Kaya HK (1999) Improved field and greenhouse efficacy with a combination of entomopathogenic nematode and Bacillus thuringiensis against scarab grubs. Biol. Control.14, 37-44.

13. Rovesti L and Dese KV (1990) Compatibility of chemical pesticides with the entomopathogenic nematodes, Steinernema carpocapsae Weiser and $S$. feltiae Filipjev (Nematoda: Steinernematidae). Nematologica .36, 237-245.

14. Selvan S, Campbell JF and Gaugler R (1993) Density-dependent effects on entomopathogenic nematodes (Heterorhabditidae and Steinernematidae) within an insect host, J. Invertebrate Pathology, 62, 278-284. 
15. Shapiro-llan DI, Mizell RF and Campbell JF (2002) Susceptibility of the plum curculio, Conotrachelus nenuphar, to entomopathogenic nematodes. J. Nematol. 34, 246-249.

16. Singh SP (1994) Technology for production of natural enemies. Project Directorate of Biological Control, Bangalore, India. Technical Bulletin, No (4) 221.

17. Stark JD (1996) Entomopathogenic nematodes (Rhabditida: Steinernematidae): toxicity of Neem. J. Econ. Entomol. 89, 68-73.

18. Stiling PD (1992) Introductory Ecology, Prentice Hall Engewood Cliffs, NJ.

19. Thurston GS, Kaya HK and Gaugler R (1994) Characterizing the enhanced susceptibility of milky disease-infected scarabaeid grubs to entomopathogenic nematodes. Biol. Control, 4, 67-73.
20. Tkaczuk C, Labanowska BH and AugustyniakKram A (2005) The potential of entomo pathogenic fungi and nematodes against strawberry root weevil Otiorhynchus ovatus L. (Coleoptera, Curculionidae). IOBC/WPRS Bulletin, 28, 173-177.

21. White GF (1927) A method for obtaining infective nematode larvae from culture. Science. 66, 302-303.

22. Woodring JL and Kaya HK (1988) Steinernematid and Heterorhabditid Nematodes: A Handbook of Biology and Techniques. Arkansas Agricultural Experiment Station. Southern Cooperative Series Bulletin, 331.

23. Zimmerman G (1996) Microbial control of vine weevil. Mitteilungen der Biologischen Bundesanstalt für Landund Forstwirtschaft Berlin-Dahlem, 64-69. 